\title{
TRATAMIENTO DEL FALSO TESTIMONIO EN LAS LEYES DE TORO
}

\author{
Christian Rodríguez Villalobos \\ Profesor de Historia del Derecho \\ Universidad Católica del Norte \\ Sede Coquimbo
}

Nos proponemos en las líneas que siguen formular algunos comentarios sobre la regulación del delito de falso testimonio en una ley castellana de la Edad Moderna, como son las llamadas Leyes de Toro, conjunto de 83 leyes dictadas por la Corona Castellana, en el año 1505 , al momento de jurar como nueva soberana de ese reino, doña Juana, apodada "la loca". Estas leyes de Toro, llamadas así porque se dictaron en la localidad de Toro, perteneciente al reino de Castilla, responden a un propósito de más largo alcance. En efecto, al despuntar el siglo XVI, la Corona de Castilla sufre las transformaciones que son consecuencia de la aparición del Estado moderno, ente que ahora encarna la organización del poder en los países de Occidente; en el caso concreto, obra de los Reyes Católicos, lo que se traduce, entre otros aspectos, en un crecimiento del aparato administrativo y de las funciones tradicionales que hasta ese momento cumplía el Estado. Este fenómeno lleva aparejado un aumento de la legislación, aún mayor que el que se venía desarrollando desde la época de Alfonso $X$ (fines del siglo XIII).

Precisamente en este contexto se insertan estas leyes, tienen el propósito de establecer un sistema de prelación o de jerarquía en la aplicación de las fuentes del derecho por parte de los operadores jurídicos- empleando un término actual- que en aquella época tienen ante sí un farragoso conjunto de normas jurídicas de creación real, foral o judicial, amén de estatutos particulares de carácter personal. Aunque no es el primer intento por estructurar sistemáticamente el derecho castellano, tiene de valioso que desde su dictación el derecho de creación real o estatal, se comienza a imponer desde la estructura del poder en forma paulatina hasta dejar relegado a la especulación teórica al derecho de raíz romano-canónica.

Precisado el objeto de estas leyes y el contexto histórico- jurídico de su dictación, entremos al análisis de la última de estas leyes, la número 83 , que como se señaló trata del delito de falso testimonio.

Al efecto, se procederá con un criterio dogmático, lo que mirado desde la ciencia histórica significa aplicar los conceptos y categorías actuales relativas a esta figura delictiva, a la realidad de la época en que se dictó.

La ley 83 de Toro, señala: "Cuando se probare, que algún testigo depuso falsamente contra alguna persona, o personas en alguna causa criminal, en la cual sino se averiguase su dicho ser falso, aquel, o aquellos contra quien depuso merescia pena de muerte, u otra pena corporal, que al tal testigo, averiguándose como fue falso, le sea dada la misma pena en su persona, e bienes, como se le debiera dar a aquel, o a aquellos contra quien depuso, seyendo su dicho verdadero, caso que en aquellos contra 
quien depuso no se ejecute la tal pena, pues por él no quedó de dargela ; lo cual mandamos que se guarde y ejecute en todos los delitos de cualquier calidad que sean, y en las otras causas criminales, e civiles, mandamos que contra los testigos que depusieron falsamente se guarden y ejecuten las leyes de nuestros reinos que sobre ello disponen" 1 .

La regulación de los delitos aparece en la generalidad de los textos castellanos medievales al final del cuerpo normativo, a modo de colofón.

¿Qué nos dice esta prescripción y cuál es su sentido? Conviene tener presente, que la necesidad de regular y sancionar, eventualmente, las deposiciones de testigos en los juicios cuando han faltado a la verdad representa la reacción de la sociedad, desde tiempos inmemoriales, ante actuaciones de miembros del cuerpo social que conllevan a la descomposición y descrédito de la prueba testimonial, única posible en muchas ocasiones, apareciendo como imperativo del cuerpo social la salvaguardia de este medio probatorio y la protección de la administración de justicia.

Dispone la presente ley que cuando algún testigo declare falsamente contra alguna persona en causa criminal, se le impondrá la misma pena que se le daría a aquel contra quien depuso, aun cuando no se aplique dicha pena.

Lo anterior supone lo siguiente:

Que se trate de causa criminal.

Que la declaración del testigo sea falsa, es decir, que falte a la verdad.

Que la declaración sea hecha contra una persona, entendiéndose la expresión "persona", como parte en sentido procesal, pues de no ser así la sanción que pende contra ella no tendría sentido.

Que aunque no se aplique la perta al imputado, porque se averiguó la falsedad de la declaración, de todas formas se sanciona al testigo mendaz con la misma pena señala al delito.

La ley distingue las causas criminales que tienen señalada pena de muerte $u$ otra corporal, de las civiles y el resto de las criminales, o sea, que no tienen señalada pena de muerte u otra corporal (caso este último de escasa frecuencia en el sistema punitivo de la época, donde la aplicación de penas corporales era la regla general). Nos interesa la primera parte, por ser los casos de mayor gravedad.

2) Es preciso que el testigo mienta, cuyas formas de comisión del delito son dos, afirmar lo que es falso o negar lo que es verdadero. En la ley 1, Título 7, Partida 7, se dice que falsedad es mudamiento de la verdad.

Es necesaria, naturalmente, la conciencia de la inexactitud de lo afirmado, que es el dolo propio de todo delito.

En este punto se presentan varias situaciones que dicen relación, entre otras con el iter criminis y el concurso con el delito de perjurio, las que no son tratadas por los comentaristas de la época dado el nulo desarrollo de una ciencia penal. 
La Ley se refiere a las declaraciones que causan un daño o perjuicio, y no las favorables, que también pueden prestarse en juicio, y que afecten a todo aquel a quien se presume responsable de algún hecho delictivo, es decir, el inculpado en la terminología de la moderna ciencia penal. No se pronuncia la ley ni tampoco los comentaristas, sobre la aplicación de esta ley a otras personas que cooperan con la administración de justicia desenvolviendo su actuación en una órbita semejante aunque no igual al testigo, caso del perito y del intérprete; sin duda que no se pudo representar la ley la posibilidad de comprender a estos sujetos por razones de desarrollo de la ciencia penal.

Este es el punto que merece mayores comentarios y respecto del cual se presentan las mayores controversias entre los comentaristas de la época.

Una primera controversia dice relación con el caso en que al inculpado (reo en la ley) no se le aplique la pena por haberse descubierto la falsedad del testimonio, si de todas formas se aplicaba dicha pena al testigo falso. Los tratadistas, fundándose en la ley 26, título 11, Partida 3, referente a este delito que prescribe: "E si por su testimonio mentiroso fuese alguno muerto o lisiado, que reciba el mismo otra tal pena", tal cual Sancho Llamas y Molina ${ }^{2}$, quien señalaba que las opiniones se dividen entre quienes piensan que la pena se aplica en todo caso y los que sostienen que sólo en el caso que se aplique la pena al reo. Atendiendo al tenor de la ley, pareciera que la pena al testigo falso se aplica en todo caso, es decir se haya ejecutado o no la pena en el reo, opinión que es más conforme con el bien jurídico que protege la disposición, que en la terminología penal moderna sería un delito de peligro abstracto, lo que quiere decir que el falso testimonio aunque no haya sido considerado por la sentencia como prueba del hecho sobre el cual recae, de todas formas se sanciona. Este es el criterio que prevalece respecto de este delito en la generalidad de las legislaciones modernas.

Un segundo punto objeto de discusión, es el relativo al número de testigos necesarios para que tenga lugar la hipótesis legal. La duda surgía por cuanto en la legislación castellana de la época (ley 32, título 16, Partida 3) y ta doctrina, era necesario al menos la declaración de dos testigos para hacer prueba respecto a algún hecho, por ende, siendo uno sólo el testigo que depuso falsamente no se verificaría el delito.

Un sector de la doctrina, señala que está comprendido en la ley en comento el caso del testigo singular, fundando este parecer en que la obligación de decir la verdad rige para todos, sea uno o más los testigos.

Otro sector es de opinión que no se comprende en la decisión de la ley de Toro, el caso del testigo singular por cuanto no se verifica la condición procesal para hacer prueba, según la ley 32 , título 16 , Partida 3.

En realidad, ambos sectores de la doctrina confunden lo que son las condiciones para que un hecho del proceso se tenga por cierto, o sea, el hecho probado, con el objeto de la ley 83 de Toro, cual es que el falso testimonio se pena en todo caso, aunque se le aplique o no la pena al inculpado. Obviamente, esto último supone que se descubra el falso testimonio en el curso del proceso.

Relacionado con lo anterior, se señala un tercer problema. El caso en que dos testigos, ahora verídicos, hacen prueba sobre la culpabilidad del inculpado, y un tercer 
testigo (puede ser dos o más) depone falsamente sobre su culpabilidad. El comentarista citado ${ }^{3}$ se hace cargo de las opiniones que circulaban en aquella época sobre esta cuestión, señalando que algunos opinaban que aunque se descubriera y probara el falso testimonio no dejaría de aplicársele la pena al reo, en consecuencia la declaración sería ineficaz para arribar a una condena con ese sólo testimonio, requiriéndose por la ley en comento que la declaración sea tan eficaz y necesaria como para provocar la condena capital, lo que no ocurre en la especie, y por tanto, no es punible el testigo falso en este caso.

Estando en desacuerdo con la expresada doctrina nuestro autor se inclina más por sancionar al testigo falso en el caso propuesto, en conformidad al tenor de la ley de Toro, en la parte que señala: "pues por él (se refiere al testigo falso) no quedó de dárgela", y al objeto que persigue, cual es sancionar estos atentados contra la administración de justicia.

Una consideración final se podría esbozar aún, y es la que dice relación con el juramento previo que debe efectuar el testigo antes de deponer en juicio.

En la ciencia penal actual, el jurar en falso o mentir bajo juramento, es decir, lo que se conoce como perjurio, constituye un tipo penal distinto que el falso testimonio, por cuanto puede verificarse ante autoridades distintas a la judicial. "Si se miente bajo juramento ante la autoridad judicial, declarando como testigo, surge un concurso aparente de leyes entre el falso testimonio y el perjurio, que se resuelve a favor del falso testimonio, tanto por especialidad como por consunción. El perjurio es un delito residual o subsidiario, que comprende todos los casos en que se miente a una autoridad bajo juramento, salvo aquellos en que se declara como testigo" ${ }^{14}$.

Sin perjuicio que tampoco se establece en la tantas veces citada ley una distinción expresa en este punto, la mayoría de los comentaristas incurría en confusiones al tratar de determinar la punibilidad del testigo que mintió bajo juramento o sin él, limitándose a distinguir si exigía la ley a la época de la declaración la formalidad del juramento, siendo punible la conducta en caso afirmativo, signo inequívoco de que tampoco se distinguía netamente ambas figuras delictivas.

\footnotetext{
3 LLAMAS Y MOLINA (n. 1), pp. 570-571.
}

4 ETCHEBERRY, Alfredo, Derecho Penal (Jurídica de Chile, Santiago de Chile 1998) 4, p. 193. 